
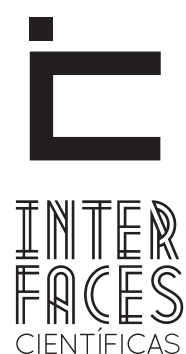

EDUCAÇÃO

ISSN IMPRESSO 2316-333X

ISSN ELETRÔNICO 2316-3828

Dossiê

\title{
AUXÍLIO AOS ALUNOS POBRES NAS ESCOLAS DE PRIMEIRAS LETRAS EM MINAS GERAIS NO SÉCULO XIX
}

Raquel Menezes Pacheco ${ }^{1}$

\section{RESUMO}

Este artigo tem por objetivo refletir sobre o início do processo de escolarização dos alunos pobres em Minas Gerais, no século XIX. Buscamos compreender, nesse processo, a construção sócio-histórica da designação "aluno pobre" pelos discursos em defesa da instrução pública que se relacionavam a práticas para viabilizar a frequência desses alunos às aulas públicas de primeiras letras. Com base em uma análise documental, utilizando como fontes, jornais da época, correspondências recebidas pela presidência da província, ofícios sobre a instrução pública e a legislação produzida, foi possível compreender o processo de atribuição de responsabilidades ao governo para a viabilização da frequência dos alunos pobres às escolas de primeiras letras na província de Minas Gerais. Pudemos acompanhar o desenvolvimento de uma estrutura burocrática amparada legalmente, que sustentava práticas anteriormente realizadas, visando a compra de materiais e livros para os alunos necessitados. Percebemos também a construção de representações, por meio de leis, requerimentos, ofícios, de sujeitos que fariam parte das escolas brasileiras desde então: os alunos pobres, que necessitavam do amparo do governo provincial para frequentar as escolas e assim, receber os ensinamentos básicos, princípios e valores, para se tornarem adultos civilizados.

\section{PALAVRAS-CHAVE}

História da Educação. Minas Gerais. Século XIX. Alunos Pobres. Frequência. 


\section{ABSTRACT}

This article aims to analyze the process of poor student's education in Minas Gerais in Brazilian 19 $19^{\text {th }}$ century. We seek to understand, in this process, the socio-historical construction of the term "poor student ", by speeches in defense of public education. These speeches are related to practices to enable the frequency of these students to elementary public school. Based on documentary analysis as newspapers, governmental correspondence and legislation, it was possible to understand the process of assigning responsibilities to the government to rescue the frequency of poor students in the elementary schools in the province of Minas Gerais. We could understand the development of a bureau- cratic structure that supported practices previously undertaken in order to purchase materials and books to the needy students. We also realize the construction of representations (through laws, petitions, letters) of a kind of students who would be part of Brazilian schools since then: the poor students, which needed governmental resources to be frequent at school and receive the basic teachings principles and values, to be civilized adults.

\section{KEY-WORDS}

History of Education. Minas Gerais. $19^{\text {th }}$ Century. Poor Students. Frequency.

\section{RESUMEN}

Este artículo tiene por objetivo reflexionar sobre el inicio del proceso de escolarización de los estudiantes pobres de Minas Gerais, en el siglo XIX. Buscamos comprender, en ese proceso, la construcción socio-histórica de la designación "estudiante pobre" por los discursos en defensa de la educación pública que se relacionaban a prácticas para viabilizar la frecuencia de esos estudiantes a las escuelas públicas de primeras letras. Con base en un análisis documental, utilizando como fuentes, periódicos de la época, correspondencias recibidas por la presidencia de la provincia, oficios sobre la instrucción pública y la legislación producida, fue posible comprender el proceso de asignación de responsabilidades al gobierno para la viabilización de la frecuencia de los estudiantes pobres a las escuelas de primeras letras de la provincia de Minas
Gerais. Pudimos seguir el desarrollo de una estructura burocrática amparada legalmente, que sustentaba prácticas realizadas anteriormente, permitiendo la compra de materiales y libros para los alumnos necesitados. Percibimos también la construcción de representaciones, a través de las leyes, las peticiones, oficios, de sujetos que serian parte de las escuelas brasileñas desde entonces: los estudiantes pobres, que necesitaban del amparo del gobierno provincial para asistir a las escuelas y así recibir las enseñanzas básicas, principios y valores, para convertirse en adultos civilizados.

\section{PALABRAS CLAVE}

Historia de la Educación. Minas Gerais. Siglo XIX. Los Estudiantes Pobres. Frecuencia. 


\section{INTRODUÇÃO}

Este artigo tem por objetivo refletir sobre o processo de escolarização de alunos pobres em Minas Gerais no período imperial brasileiro. Buscamos compreender, nesse processo, a construção sócio-histórica da designação "aluno pobre" pelos discursos em defesa da instrução pública que se relacionavam a práticas para viabilizar a frequência desses alunos às aulas públicas de primeiras letras.

Segundo Moysés Kuhlmann (1998), os estudos sobre a infância são favorecidos pela maior abundância de fontes que se referem aos meios mais abastados da população, resultando na maior produção de pesquisas que tematizam esses grupos. Em se tratando da criança pobre, predominam os estudos ligados às instituições voltadas para o cuidado e proteção da infância, tais como orfanatos, asilos, escolas de ofícios (KUHLMANN, 1998; VEIGA, 2008). Outros estudos tematizam as crianças índias, negras, brancas e mestiças, as crianças “infratoras”, as crianças trabalhadoras, etc., que permitem compreender as múltiplas vivências infantis em diversos contextos históricos e culturais. Apesar do grande volume de trabalhos recentes produzidos pela historiografia da infância na interlocução com a historiografia da educação, o século XIX não tem sido tão explorado. Trata-se de um período histórico particularmente fértil, marcado pelas iniciativas governamentais em organizar a instrução pública e disseminar a instrução para as "classes inferiores" da sociedade.

Na sociedade mineira dos oitocentos, a extensa população livre e pobre era constituída, na sua maioria, por mestiços e negros forros e fugidos. Quando possuíam alguma ocupação, essa não possibilitava, em geral, uma vida estável, com moradia, alimentação e vestimenta, além de possuírem hábitos relacionados à promiscuidade e criminalidade (SOUZA, 1994). Esses elementos contribuíam para a desqualificação das classes pobres para a adequada educação das novas gerações, por parte dos discursos pedagógicos e governamentais. Isso se agravava, sobretudo em se tratando de um Estado- Nação que buscava se legitimar enquanto moderno e civilizado, tal como as nações européias (JINZENJI, 2002).

Segundo Cynthia Veiga (2008), a escola pública elementar do século XIX era destinada, principalmente, às crianças negras, mestiças ${ }^{2}$ e pobres, por serem essas as crianças que deveriam ser alvo do discurso civilizador. "Entendia-se que a educação escolar teria a dupla função de proteger a infância das ameaças do mundo e transformá-la, formando-a nos moldes de um adulto civilizado" (GOUVÊA; JINZENJI, 2006, p.122). 0 professor deveria, assim, ser o sujeito responsável por desenvolver nas crianças qualidades morais e racionais para que elas se tornassem cidadãos civilizados.

\section{INSTRUÇ̃̃O E EDUCAÇ̃̃O DOS ALUNOS POBRES}

A Carta de Americus: Idéas elementares sobre hum systema de educação nacional, transcrita em nove edições (10/02/1826 a 03/03/1826) do periódico $O$ Universal, impresso em Ouro Preto, província de Minas Gerais, dividia a educação em três campos: físico, intelectual e moral. A Carta caracterizava a moral como característica adquirida por hábitos domésticos apreendidos ainda na infância através, por exemplo, do ensino de indivíduos de maior convivência familiar. De acordo com a Carta de Americus, o comportamento e o nível de instrução que possuíssem os pais influenciariam muito na educação dos filhos. Nesse mesmo argumento, no Curso Normal para Professores de Primeiras Letras, o Barão Dè Gerando afirmava que a origem social e as condições em que as crianças pobres estivessem submetidas influenciariam negativamente, conformando, nos mesmos, "diferentes características físicas, emocionais e comportamentais" (JINZENJI, 2002, p.57).

2. Para maior aprofundamento sobre a instrução de crianças negras e pardas em Minas Gerais, no século XIX, ver FONSECA (2009a). 
Os discursos relacionados à escolarização da criança pobre nesse período, ao mesmo tempo em que desqualificavam as famílias das classes pobres, buscavam legitimar a escola como substituta da família tanto para instruir - enriquecer as faculdades intelectivas com os conteúdos elementares, como ler, escrever e as quatro operações matemáticas - como para educar - desenvolver as faculdades morais. Instruir e educar são inseparáveis, sendo a instrução subordinada à educação (JINZENJI, 2002).

Analisar os discursos acerca do processo de escolarização da infância, nesse período, significa também compreender o processo de transformação da criança em aluno; no discurso pedagógico, o aluno é a criança escolarizada (BOTO, 2000). Nesse sentido, como nos lembra Narodowski (2001), é necessário desnaturalizar a relação historicamente construída entre aluno e criança, buscando compreender essa configuração não como algo dado, necessário, mas como espaço de possibilidades. No caso do objeto específico de reflexão deste texto, buscamos compreender as condições e necessidades que contribuíram para a constituição dos alunos pobres como categoria sócio-histórica que, ao mesmo tempo que foi produzida, também produziu práticas que caracterizaram a escola daquele período.

Conforme Veiga (2008), a escola pública do século XIX foi um dos espaços a produzir a identidade do aluno pobre. Entendemos que, além de contribuir para a construção dessa identidade, a escola, os professores, delegados de círculos literários ${ }^{3}$ e até mesmo a própria legislação, passaram a elaborar representações acerca do aluno pobre como aquele que necessita, além da filantropia e da ajuda das instituições religiosas, também de políticas específicas por parte do governo provincial, que permitissem sua efetiva participação nos processos educativos escolares que estavam em processo de institucionalização $0^{4}$.

3. A expressão "Círculo Literário" refere-se a uma porção do território da província mineira cuja extensão era demarcada segundo a densidade da população. A princípio, Minas Gerais foi dividida em 15 Círculos Literários. A sede de cada um localizava-se em uma cidade ou vila importante da circunscrição (INÁCIO, 2003).

4. "No mundo luso-brasileiro do século XVIII e nas primeiras décadas do sé-

\section{3 “OBJECTOS INDISPENSAVEIS PARA O ENSINO DE ALUMNOS POBRES"}

O papel assumido pelo Estado no projeto de escolarização da infância pobre no século XIX envolveu, num primeiro momento, o estabelecimento de escolas, a contratação de professores para o provimento desses estabelecimentos e a produção de aparatos legais para organizar o ensino público. Posteriormente, dificuldades de várias naturezas fizeram com que o seu papel se ampliasse e passasse a ser também o de viabilizar a presença desses alunos pobres na escola. Segundo o discurso dos grupos políticos dirigentes, os motivos que impediam o bom andamento da instrução na província mineira se dividiam entre os professores, que careciam de formação adequada e de experiência e os pais dos alunos que, não compreendendo a importância da instrução, não se esforçavam em enviá-los à escola. Um outro motivo bastante ressaltado se referia à falta de condições materiais, nos casos dos alunos extremamente pobres. Faltava-lhes não só os materiais necessários para frequentar as aulas, como também o vestuário, o que causava o elevado número de ausências. Assim, com base nos mapas e relatórios acerca da situação da instrução pública, afirmava-se:

\begin{abstract}
Ve se porem dos mesmos documentos que o numero dos matriculados não é inferior a 9:000, sendo já reconhecido que a $4^{a}$ parte delles pouco mais ou menos deixa de ter a fequencia habitual de 10 dias em cada mez, e isto por diversas razões bem obvias, como sejão as enfermidades, as occupações domesticas, e ainda mesmo a falta de vestimenta, e de outros objectos indispensaveis, quando os Pais são indigentes. (O UNIVERSAL, 26 fevereiro 1841).
\end{abstract}

A primeira Lei Geral do Ensino, de outubro de 1827, em seu artigo 5ª afirmava que os utensílios necessá-

\footnotetext{
culo XIX a instrução e a assistência estiveram muito próximas, envolvendo o Estado e a Igreja, e movidas tanto pela necessidade da civilização dos povos por meio da disseminação dos valores morais e religiosos. Assim, a ideia de educação para as camadas mais baixas da população esteve profundamente associada à difusão da doutrina cristã e à formação profissional como meios de controle (...) 0 ensino das primeiras letras visava fundamentalmente facilitar o aprendizado da doutrina, sem implicar a criação de possibilidades de ascensão social pela educação (...)” (FONSECA, 2009b, p.101).
} 
rios para as escolas do ensino mútuo seriam arranjados à custa da Fazenda Pública (IMPÉRIO DO BRASIL, 1827). Previa-se o fornecimento dos materiais para viabilizar os estudos sem, no entanto, mencionar as especificidades do público frequentador das escolas.

De acordo com Inácio (2003), foi no ano de 1837, dez anos após a Lei Geral do Ensino, que a província de Minas Gerais, pela primeira vez, passou a incluir no seu orçamento, gastos específicos com a instrução de meninos pobres. Antes da publicação dessa Lei, de número 80, em fala na sessão ordinária de 1837 , o presidente Antônio da Costa Pinto, fez o seguinte relato questionando a dificuldade dos alunos pobres permanecerem nas escolas, sem auxílio financeiro do governo.

Garantindo a Constituição a Instrucção primaria, e gratuita á todos os Cidadãos, esta salutar disposição á respeito de meninos pobres será quase illusoria, se o Governo não for authorisado a dispender alguma quantia com o fornecimento de papel, exemplares, compêndios, e outros objetos de pouco valor, que lhe são indispensaveis. Que importa, que estes desgraçados freqüentem as Escolas, se thes fallecem todos os meios para conseguirem a instrucção elementar? E note-se que, taes individuos são os que devem deixar mais cedo as Escolas, para que possão opportunamente applicar-se ao modo de vida, de que hão de tirar os meios de subsistencia. O Governo pois convencido da proficuidade das medidas indicada, aguardando em geral a deliberação, que houverdes de tomar á este respeito. (PINTO apud INÁCIO, 2003, p.53, 54).

A publicação da Lei n. 80, em abril de 1837, talvez por influência da fala do presidente da província, autorizou, no período de julho de 1837 a junho de 1838, o presidente da província a dispender 79:449\$200 réis ${ }^{5}$

5. Este valor não foi o mesmo para os anos subsequentes. A Lei n.570 de 1851, por exemplo, que fixava as despesas provinciais entre meados de 1852 e meados de 1853, estabeleceu em seu capítulo 1, que tratava de despesas ordinárias, o valor de 92:000\$000, que deveria ser gasto "§14. ${ }^{\circ}$ Com a instrucção publica, ordenado do Director, Professores de instrucção intermédia, primaria de $1 .^{\circ}$ e $2^{\circ} .^{\circ}$ gráo, da aula normal, das aulas providas, ou que forem providas, em virtude da Lei n. ${ }^{\circ} 511$ de 3 de Julho de 1850, alugueres de casas, e objectos necessarios ao ensino dos meninos pobres" (MINAS GERAIS, 1851).
$\S 2 .^{\circ}$ Com a Instrucção Publica comprehendendo-se as Aulas de estudos intermédios; as Escolas do $1 .^{\circ}$, e $2 .^{\circ}$ gráu; os objectos n`estas indispensaveis para o ensino dos meninos pobres, e o aluguer de cazas para as Escolas do Ouro Preto, e S. João d`El Rei, podendo tambem extender esta providencia ás que forem habitualmente frequentadas por mais de sessenta alumnos (...) (MINAS GERAIS, 1837, Lei n.80).

O surgimento da necessidade de viabilizar a permanência de alunos pobres nas escolas também foi presenciado na província do Mato Grosso no mesmo período. Em 1837, com a publicação da primeira Lei provincial sobre a instrução, Xavier (2008) afirma que a mencionada Lei quase não responsabilizava o governo da Província no que diz respeito ao atendimento dos alunos pobres. De acordo com a autora, a responsabilidade do governo se limitava à distribuição dos prêmios escolares aos meninos pobres de melhor desempenho nas aulas públicas. A quota para a compra de materiais para a instrução desses alunos estava relacionada à cobrança de uma multa pelo governo da província de Mato Grosso, aos pais dos alunos (que não eram considerados pobres), caso seus filhos fossem infrequentes. Assim, Ana Paula Xavier (2008) aponta a fragilidade do governo provincial em manter e ampliar seu sistema de ensino, uma vez que a população que frequentava as aulas públicas na província era, em sua grande maioria, empobrecida e por essa razão, isenta da multa. Mesmo não sendo atendidos, na maior parte das vezes, na província matogrossense, professores não cessavam em levar requerimentos aos presidentes da Província, de utensílios para as aulas e para o ensino de alunos pobres. Podemos verificar como as demandas dos professores foram elementos essenciais para produzir a necessidade do Estado em garantir a permanência da maior parte da população das escolas de instrução primária.

Em Minas Gerais, os pedidos de objetos utilizados nas escolas, feitos por professores e posteriormente por delegados de círculos literários aos presidentes da Província, se multiplicaram após a publicação da Lei n. 80, passando a apontar os alunos pobres, até 
então, praticamente inexistentes nos pedidos enviados, como destinatátios de tais utensílios.

Além da denominação alunos pobres, também encontramos outras expressões para designar os mesmos sujeitos, como por exemplo, "alumnos nimiamente pobres” (Códice 234, 15/08/1839). Há também referências, embora poucas, às "meninas pobres" (Códice 234, 19/08/1839). No final da década de 40, em um dos pedidos, a caracterização da pobreza dá lugar à necessidade, quando nos deparamos com os termos "meninos mais necessitados" (Códice 360, 27/07/1847). Apesar da mudança da expressão, a condição de pobreza dos alunos já estava vinculada às suas necessidades, pelo menos, àquelas necessidades que surgiam estritamente ligadas ao processo de escolarização. 0 Delegado do $2^{\circ}$ Circulo Literário, Fortunato Rafael, dizia ser "conhecedor das necessidades de grande numero de alumnos pobres" sendo, segundo ele, mais de sessenta no seu círculo. O Delegado, nessa oportunidade, reclamava com o então vice-presidente da Província, Antônio da Costa Pinto, já ter gasto grande quantia com a compra de "compendios de doctrina Christan, pennas de lapis, de escrever", entre outros objetos para a instrução dessas crianças (SP PP 1/42, Caixa 08, 14/08/1837).

Delegados de quase todos os dezesseis Círculos Literários, da província de Minas Gerais, enviaram orçamentos, fizeram pedidos aos presidentes, requereram dinheiro para o pagamento de utensílios que seriam utilizados nas escolas em função dos alunos pobres. Os orçamentos e pagamentos realizados giraram de 15 e 270 mil réis na década de 1840, gastos, em geral, com penas, lápis, canivetes, preparos de tinta, resmas de papel, compêndios, tabuadas e silabários ${ }^{6}$.

6. Conseguimos registrar alguns desses documentos enviados à presidência da província de Minas Gerais, por delegados literários, durante a década de 40 do século XIX. Como, por exemplo: Delegado do $1^{\circ}$. Circulo Literário (Códice 360, 20/02/1846); Delegado do $2^{\circ}$. Circulo Literário (Códice 267, 14/08/1840), (Códice 304, 06/03/1843), (Códice: 360, 29/05/1844; 29/12/1844; 23/05/1845; 01/07/1847; 27/07/1847); Delegado do $3^{\circ}$ Circulo Literário (Códice 267, 02/03/1840), (Códice 360, 18/10/1845; 20/11/1845; 20/12/1845; 11/10/1848); Delegado do $4^{\circ}$ Circulo Literário (Códice 360, 08/08/1845; 03/03/1846); Delegado do $5^{\circ}$ Circulo Literário
O grande volume de pedidos de compra de materiais e livros indica que não era desprezível a parcela da população escolar, nas primeiras décadas de funcionamento das escolas públicas de primeiras letras, que não dispunha das condições necessárias para frequentá-la. As demandas eram materializadas tanto por professores quanto por delegados, requerendo uma melhor forma de sistematizar os procedimentos que ameaçavam fugir ao controle do governo. Em uma resposta dada a um Delegado pelo Presidente da Província, distinguindo bem as funções que deveriam ter professores e delegados de círculos literários diante da necessidade de pedir, orçar, comprar e pagar por objetos destinados à instrução pública: “(...) recommendo-lhe que não consinta que os Professores do seu Circulo fação por si mesmo tais despezas, que previamente devem ser authorisados, pelo Governo, e feitas pelos Delegados, e muito menos que se demore tanto a apresentação de taes contas (...)" (Códice 360, 29/08/1844).

0 grande montante gasto com a manutenção dos alunos pobres era motivo de preocupação do governo, que buscava manter o controle financeiro otimizando as compras: apenas os utensílios estritamente indispensáveis à instrução desses alunos, e nada além da quantidade suficiente para tal.

O Presidente da Provincia tendo prezente o Officio do
Sr. Delegado do $6^{\circ}$ Circulo Litterario (...) em que presta
as informações exigidas a cerca da requisição do Pro-
fessor Publico de Instrucção primaria da Serra de San-
to Antonio do Grão Mogol, resolveo authorisalo para
prestar aos alumnos pobres tanto da dita Aula como
da do Arraial da Chapada os objectos indispensaveis
para uzo dos mesmos, apresentando depois a conta
do que despender para ser pagas. O Presidente da Pro-
vincia dando esta providencia lembra ao Sr. Delegado

(Códice 360, 20/11/1846); Delegado do $6^{\circ}$ Circulo Literário (Códice 360, 08/08/1848); Delegado do $7^{\circ}$ Circulo Literário (Códice 360, 24/04/1846); Delegado do $8^{\circ}$ Circulo Literário (Códice 360, 30/07/1845; 24/04/1849); Delegado do $9^{\circ}$ Circulo Literário (Códice $360,12 / 06 / 1844 ; 18 / 02 / 1845$; 20/03/1845; 05/10/1845; 18/08/1848; $11 / 10 / 1848)$; Delegado do $11^{\circ}$ Circulo Literário (Códice 267, 29/08/1839), (Códice 360, 15/08/1845; 24/01/1846; 24/07/1846; 23/03/1847); Delegado do $15^{\circ}$ Circulo Literário (Códice 360, 19/06/1847); Delegado do $16^{\circ}$ Circulo Literário (Códice 360, 07/10/1844; 30/07/1845; 23/08/1848). 
que deve procurar, quanto for possivel, modificar as quantias pedidas, e orçadas para uma, e outra Escola, tendo em vista a necessaria economia, por quanto attendendo-se ao grande numero de alumnos que frequentão as Aulas da Provincia, e que se podem chamar pobres, uma despeza proporcional á de que se trata excederá muito a quota consignada para taes objectos. (Códice 267, 14/03/1840).

A grande quantidade de pedidos e orçamentos que chegavam para o governo provincial resultava, por vezes, na não autorização da compra de objetos para o ensino de meninos pobres, por falta de recursos financeiros. Ainda na década de 1840, o presidente Quintiliano da Silva em resposta ao delegado do $11^{\circ}$ Círculo Literário comunicou que não seria possível "atender seu pedido sobre a quantia $\mathrm{p} /$ os objetos dos meninos pobres pois a quota destinada $\mathrm{p} /$ isso acabou e deve essa quantia ser pedida a Assembléia junto ao pedido que há de fazer (Códice 360, 10/11/1846)”.

Nos primeiros anos da década de 1850, continuaram havendo pedidos para compra de materiais e vários foram concedidos pelo presidente da província de Minas Gerais, Antônio José Ribeiro Bhering $^{7}$. O Regulamento n. 28, de 1854 estabeleceu as bases e disposições que reorganizariam a instrução pública na província de Minas Gerais. Nele foram apresentadas considerações importantes acerca do custeio e fornecimento dos objetos necessários para a instrução das escolas públicas, sistematizando as condições e instâncias para o provimento de objetos e livros às escolas, o que acabou afetando o fornecimento de materiais para os alunos pobres. Como incumbência do Diretor Geral da Instrução Pública estavam, entre outras, a fiscalização de "quaesquer quantias dispendidas com objectos de Instrucção" (artigo 50); a organização do "orçamento da despeza que houver de ser decretada com o pessoal e material da Instrucção", incluindo os livros de leitura e catecismos

7. Como por exemplo, os pedidos encontrados nos documentos: (Códice 434, 09/01/1850; 14/04/1850; 30/07/1850; 04/01/1851; 22/10/1851; 01/12/1851; 01/03/1852; 02/08/1852; 30/08/1852; 01/09/1852). (artigo $7^{\circ}$ ). Ao Diretor do Círculo Literário cabia, entre algumas funções, a de verificar e atestar o estado dos utensílios das escolas (artigo 20\%). Os Visitadores dos Círculos Literários deveriam "distribuir pelos alumnos pobres os objectos necessarios ao seu ensino, á requisição dos professores” (artigo $26^{\circ}, \S 8^{\circ}$ ).

\section{CONSIDERAÇÕES FINAIS}

A breve análise aqui desenvolvida possibilita compreendermos o processo de atribuição de responsabilidades ao governo para a viabilização da frequência dos alunos pobres às escolas de primeiras letras na província de Minas Gerais. Isso se deu a partir de demandas formuladas pelos professores, delegados de Círculos Literários, visitadores de escolas, diante da baixa frequência desses alunos nas escolas. Pudemos acompanhar o desenvolvimento de uma estrutura burocrática amparada legalmente, que sustentasse práticas anteriormente realizadas, visando a compra de materiais e livros para os alunos necessitados. Juntamente a esse processo "procedimental", verificamos a produção de representações, por meio de leis, requerimentos, ofícios, de uma categoria sociohistórica que faria parte das escolas brasileiras desde então: a dos alunos pobres, antes crianças provenientes das "classes inferiores" que, pertencentes a famílias incapazes de fornecer condições mínimas de vida e de educação, deveriam ser providas pelo Estado para que nas escolas pudessem receber os ensinamentos básicos, princípios e valores, para se tornarem adultos civilizados.

\section{FONTES}

\section{Legislação}

IMPÉRIO BRASILEIRO. Lei Imperial de 15 de outubro de 1827. Disponível em: http://www.pedagogiaemfoco.pro.br/heb05a.htm. Acesso em: 04/05/2012. 
MINAS GERAIS. Lei Provincial n. 80 de 1837. Livro das Leis Mineiras. Disponível em: http://www.siaapm.cultura.mg.gov.br. Acesso em: 20/11/2013.

MINAS GERAIS. Lei Provincial n. 570 de 1851. Livro das Leis Mineiras. Disponivel em: http://www.siaapm. cultura.mg.gov.br. Acesso em: 21/11/2013.

MINAS GERAIS. Regulamento n. 28 de 1854. Livro das Leis Mineiras. Disponível em: http://www.siaapm.cultura.mg.gov.br. Acesso em: 17/02/2014.

\section{Periódico:}

Universal (O). Ouro Preto: Officina Patrícia de Barboza e Cia.; Officina Patrícia do Universal, 1825 - 1842. Disponível em http://www.cultura.mg.gov.br. Acesso em 20 de Maio de 2011.

\section{Fontes Manuscritas:}

MINAS GERAIS. Instrução Pública. Correspondências recebidas pela presidência da província (1823-1852) SP PP 1/42, caixas 1-14. Arquivo Público Mineiro.

MINAS GERAIS. Códice 234, Ofícios dos Delegados dos Círculos Literários ao Governo 1839. Arquivo Público Mineiro.

MINAS GERAIS. Códice 267, Portarias da Presidência aos Delegados Literários 1839-1840. Arquivo Público Mineiro.

MINAS GERAIS. Códice 360, Ofícios sobre Instrução Pública. Arquivo Público Mineiro.

MINAS GERAIS. Códice 434, Ofícios Dirigidos ao Governo pela Diretoria Geral de Instrução Pública 1849-1853. Arquivo Público Mineiro.

\section{REFERÊNCIAS}

BOTO, Carlota. A pedagogia científica em Portugal e a alquimia do magistério: vocação, criatividade, entusiasmo, conteúdo, disciplina. In: História da Educação. Pelotas: Editora da UFPel, n. 8, set. 2000, p. 23-45.

FONSECA, Marcus Vinícius. População Negra e Educação: o perfil racial das escolas mineiras no século XIX. Belo Horizonte: Mazza Edições, 2009a.

FONSECA, Thais Nívia de Lima e. Letras, Ofícios e Bons Costumes: Civilidade, ordem e sociabilidades na América Portuguesa. Belo Horizonte: Autêntica, 2009b.

GOUVÊA, Maria Cristina Soares de; JINZENJI, Mônica Yumi. Escolarizar para moralizar: discursos sobre a educabilidade da criança pobre (1820-1850). In: Revista Brasileira de Educação. v. 11, n. 31, jan./abr. 2006, p. 114-200.

INÁCIO, Marcilaine Soares. O processo de escolarização e o ensino de Primeiras Letras em Minas Gerais (1825-1840). Belo Horizonte: Faculdade de Educação/UFMG, 2003. Dissertação de Mestrado.

JINZENJI, Mônica Yumi. A escolarização da infância pobre nos discursos educacionais em Minas Gerais (1825-1846). Belo Horizonte: Faculdade de Educação/UFMG, 2002. Dissertação de Mestrado.

KUHLMANN Jr., Moysés. Infância e educação infantil: uma abordagem histórica. Porto Alegre: Mediação, 1998.

NARODOWSKI, Mariano. Infância e poder: conformação da pedagogia moderna. Bragança Paulista: Editora da Universidade São Francisco, 2001. 
SOUZA, Laura de Mello e. Opulência e Miséria das Minas Gerais. 4ª ed. São Paulo: Brasiliense, 1994.

VEIGA, Cynthia Greive. Escola pública para os negros e os pobres no Brasil: uma invenção imperial. In: Revista Brasileira de Educação. v. 13, n. 39, set./dez. 2008.
XAVIER, Ana Paula da Silva. Utensílios Escolares e a Escolarização da Infância Pobre no Século XIX. In: Anais do V Congresso Brasileiro de História da Educação: O Ensino e a Pesquisa em História da Educação. São Cristóvão: Universidade Federal de Sergipe; Aracaju: Universidade Tiradentes, 2008.

1. Possui graduação em Pedagogia com formação complementar em Ciências da Educação pela Universidade Federal de Minas Gerais. Mestranda em Educação, linha de História da Educação, no Programa de Pós-graduação Conhecimento e Inclusão Social em Educação, Faculdade de Educação da Universidade Federal de Minas Gerais. Belo Horizonte, Minas Gerais, Brasil.E-mail: raquelmp@hotmail.com.br

2. Professora Adjunta da Faculdade de Educação da Universidade Federal de Minas Gerais e do Programa de Pós-Graduação em Educação na mesma instituição. Possui graduação em Psicologia pela Universidade Federal de Minas Gerais. Possui Mestrado, Doutorado e Pós-Doutorado em história da educação na mesma instituição. E-mail monicayj@ufmg.br 